\title{
Design OF MASTERY-BASED TUtORIAL IN THE BRIGHTSPACE LEARNING ENVIRONMENT FOR A FIRST YEAR THERMODYNAMICS COURSE
}

\author{
Joyce Valencerina ${ }^{1}$, Douglas Ruth ${ }^{2}$, and Jillian Seniuk Cicek ${ }^{3}$ \\ Centre for Engineering Professional Practice and Engineering Education, Faculty of Engineering, University of Manitoba, \\ Winnipeg, Canada \\ 11valencej@myumanitoba.ca; ${ }^{2}$ douglas.ruth@umanitoba.ca; ${ }^{3}$ umseniuk@myumanitoba.ca
}

\begin{abstract}
University level studies can be a daunting experience for students in their first year, especially for students pursuing engineering. Not only are students expected to adapt to a new and intense learning environment, they need to develop a critical thinking approach for their coursework, which is essential in solving engineering problems. The Faculty of Engineering at the University of Manitoba uses the Brightspace Learning Environment by D2L Corporation (UM Learn) as a primary means for delivering course content, communicating with students, and assessing student performance. Of interest are the assessment tools, which can be adapted to enforce good problem solving habits and check students' learning progress. This paper discusses the design of a mastery-based tutorial for a first year thermodynamics course that provides supplementary formative assessments to ensure students have mastered course content. A survey was distributed to evaluate the online tutorial in which students expressed mixed responses to its usefulness, although many agreed that it supported learning.
\end{abstract}

Keywords: Mastery learning; Learning Management systems; tutorials; first year thermodynamics course; critical thinking skills; online learning

\section{INTRODUCTION}

Engineers use a systematic approach to problem solving in which a large, complex problem is broken down into small representative components of the real situation [9]. Problem-solving skills however, develop over time with practice [8]. Engineering students must be exposed to systematic problem solving early on in their academic careers in order to develop the necessary skills over time. Typically, before students are assigned complex design problems, they are first introduced to engineering science courses, which present principles and concepts in a way that are applicable to solving engineering problems [9]. A thorough understanding of engineering science is fundamental to solving real world problems.

Post-secondary students' relative academic placements remain fairly constant in their academic careers. Students who demonstrate a thorough understanding of fundamental concepts in engineering will often continue to demonstrate high academic performance in their succeeding courses because course content is designed to be cumulative. Conversely, students lacking the necessary mastery of foundational knowledge will likely struggle for understanding in their upper level courses [1][7]. It has been theorized that students' aptitude is directly linked to the time it takes to master coursework, therefore students with lower aptitudes require more time to master principles and concepts [6][5]. Mastery learning is a tool that addresses the time issue because it values performance over time constraints in teaching. Individualized instruction, opportunity for study and practice, and repeated formative testing and feedback form the basis of mastery learning techniques [11]. A typical curriculum would be organized into units, with regular checks on learning progress where students receive formative assessments with valuable feedback [6][11].

The greatest challenge in implementing mastery learning techniques in a post-secondary setting is a lack of instructional time [4]. Few studies document the effectiveness of mastery learning in post-secondary settings, and even fewer in undergraduate engineering $[2][10][4]$. The few studies conducted found that while students benefited from mastery learning instruction, these benefits could be increased - students and instructors both saw potential in developing methods to deliver feedback for formative assessments [2]. Learning management systems are typically used to distribute distance courses online, although more universities are adopting them to support traditional instruction [3]. Learning management systems are an efficient 
communication tool between instructors and students, well suited to providing effective and timely feedback.

This paper presents a research-based design of a online tutorial using Internet-based mastery techniques for an introductory thermodynamics course in undergraduate engineering. This tutorial was designed for use in the Brightspace Learning Environment, UM Learn, which the University of Manitoba currently uses to distribute course content. However, the concepts and principles in the design of this tutorial may be applicable in any ELearning environment. This paper will review techniques in mastery learning, as well as explore the ways in which it may be implemented in learning management systems. The tutorial design will be implemented in the 2016 Summer session course, although some aspects of it have been piloted in the 2016 Winter term. Survey data collected from those students will be discussed in this paper.

\section{MASTERY LEARNING IN AN E- LEARNING ENVIRONMENT}

\subsection{A Review of Mastery Learning Techniques}

Mastery learning is an instructional strategy that addresses the variations in rates of learning between students. It is suggested that lower aptitude students require more time to understand course material than higher aptitude students [7]. Therefore, lower aptitude students require more opportunities to understand fundamental concepts [1]. Mastery learning techniques are founded upon high quality instruction, progress monitoring and corrective feedback. Students typically attain higher achievement levels and gain more confidence in course material, as opposed to traditionally taught courses [6][11]. Mastery learning is typically applied in elementary, middle and secondary education [2], [6]. However there is potential for integrating mastery learning in a post-secondary setting due to its flexibility in implementation [10][4].

Two common mastery-learning techniques were considered for the design of the tutorial for a first year thermodynamics course in undergraduate engineering. The Learning for Mastery method (LFM) is group-based. Here, the instructor controls the pacing of formative assessments and provides individualized feedback. This method is typically implemented in elementary, middle and secondary education [4]. Another technique, the Personalized System of Instruction PSI method, is mostly self-pacing. Students are provided high quality lectures and textual material, while individual tutoring and assessment are emphasized. University students and instructors are more likely to favour PSI instruction for its flexibility [4].

\subsection{Brightspace Learning Environment}

The University of Manitoba uses the Brightspace Learning Environment by D2L (UM Learn) as a means of distributing course content and communicating between students and instructors. UM Learn is flexible in allowing instructors to design their courses within the learning management system, and for its ability to facilitate communication between instructors and students. Additionally, the Brightspace Learning Environment offers various tools for assessment. Of interest for the development of this tutorial are Quizzes and Self Assessments. The Self Assessments offer a form of formative assessment in an interactive environment where students test themselves and receive feedback instantaneously. Here, students are not evaluated on their answers. Instead, they are encouraged to use the feedback, which clarifies and reinforces concepts taught in the course, to improve their understanding of the concepts. The Quizzes, on the other hand, are graded formative assessments. This paper will discuss a tutorial design in which Quizzes and Self Assessments in the Brightspace Learning Environment may be utilized to enhance students' learning experience to support students' mastery of targeted concepts and skills.

\section{METHODOLOGY}

At the University of Manitoba, the first year thermodynamics course, Introduction to Thermal Sciences, consists of five lecture series based on five chapters in Borgnakke and Sonntag's Fundamentals of Thermodynamics text, as listed in Table 1.

The course material is cumulative. Principles learned in Chapter 1 are applied in Chapter 2, principles learned in Chapter 2 are applied in Chapter 3, and so on. The course uses three thermodynamic systems to demonstrate basic principles: the rigid vessel, the piston-cylinder, and control volume cycles. The rigid vessel is introduced first to reinforce the concepts of specific volume and density. Then, the piston-cylinder is introduced to demonstrate the principle of work with a moving piston. Finally, cycle problems facilitate the understanding of control volume systems. Students are expected to utilize thermodynamic property tables and the Ideal Gas Law to find state properties of substances and solve the problems systematically. Thus, a mastery of the early chapters will improve understanding and facilitate mastery of the later chapters.

Students are evaluated in the course through summative and formative assessments. Summative assessments include four term tests spread out through the duration of the term, and one final exam conducted at the end of the term. Each of the four term tests covers content in the first four lecture series, while students are evaluated 
Table 1: Introduction to Thermal Sciences curriculum summary.

\begin{tabular}{|c|c|}
\hline Chapter & Material Covered \\
\hline 1 & $\begin{array}{l}\text { - Review of systems, variables, and units } \\
\text { - Review of force, mass, and acceleration } \\
\text { - Review of mass and weight } \\
\text { - Specific volume and density } \\
\text { - Pressure in a cylinder with a simple piston } \\
\text { - Pressure beneath a liquid surface } \\
\text { - Manometer and barometer } \\
\text { - Temperature }\end{array}$ \\
\hline 2 & $\begin{array}{ll}\text { - } & \text { Substances and processes } \\
\text { - } & \text { Properties of substances for change of phase: } \\
\circ & \text { Saturated liquids/vapours } \\
\circ & \text { Superheated vapours } \\
\circ & \text { Compressed liquids } \\
\circ & \text { Saturated mixtures } \\
\circ & \text { Ideal gases }\end{array}$ \\
\hline 3 & 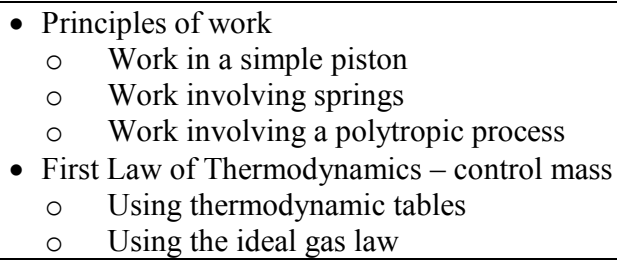 \\
\hline 4 & $\begin{array}{l}\text { - Flow phenomena } \\
\text { - Conservation of mass - control volume } \\
\text { - Conservation of energy - control volume } \\
\text { - The Air Conditioner } \\
\text { - The Gas Turbine } \\
\text { - Other processes } \\
\end{array}$ \\
\hline 5 & $\begin{array}{l}\text { - The reversible and irreversible universe } \\
\text { - The Carnot cycle } \\
\text { - Thermal efficiency } \\
\text { - Coefficient of performance } \\
\text { - Impossible, reversible, and possible machines } \\
\text { - Second Law of Thermodynamics }\end{array}$ \\
\hline
\end{tabular}

on the fifth lecture series and re-examined on the previous four chapters in the final exam. Formative assessments in the form of written assignments are assigned weekly during the fall and winter sessions, or daily during the summer session. The written assignments are intended to assess students' understanding of course material, as well as enforce proper documentation of their work, which professional engineers are required to do.

Because course material is cumulative, students who demonstrate high aptitude in the first term test, which evaluates prerequisite knowledge and the use of thermodynamic tables, for the most part continue to demonstrate high aptitude in later tests and on the final exam. However, students who struggle with the preliminary material often continue to struggle throughout the course. It is hypothesize that students may attain higher levels of achievement by mastering fundamental concepts. The tutorial design for the thermodynamics course supports all students in mastering the fundamental concepts and skills taught in the class. The tutorial is intended to support students' learning by enabling both students and instructors to diagnose areas where corrective action is required. The following section discusses the design and integration of mastery-learning methods in the thermodynamics course tutorial.

\subsection{Systematic Problem Solving and Instant Feedback}

The thermodynamic problems are designed to guide students through a systematic problem solving process with the objective of clarifying and reinforcing ideas discussed in class before assessing students' abilities in applying these concepts to the systems described above. Questions are repetitive, but varied, allowing students to approach problems in different ways and enabling a mastery of concepts. The flow chart in Fig. 1 illustrates the questions asked in the tutorial, and the chronology of their implementation.

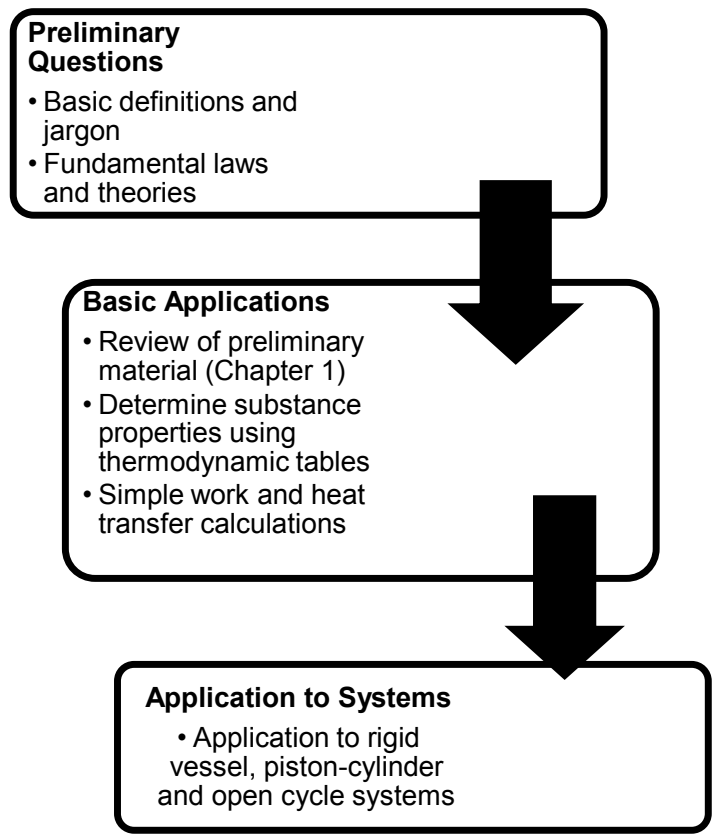

Fig. 1. Types of questions considered in the tutorial.

First a series of preliminary questions enrich students' fundamental knowledge of thermodynamic principles. These assess students' understanding of the theory learned in class, as shown in the example in Fig. 2.

The next series of questions require a basic application of thermodynamic concepts, and one or two simple calculations. These questions ensure a foundational understanding of how to apply the theory to small systems, as well as practice using the thermodynamic tables and interpolating for state properties, such as specific volume, specific internal energy and specific enthalpy. An example is illustrated in Fig. 3. 
A control surface divides the universe into what two parts:
A) The surroundings
B) The thermodynamic phase
C) The thermodynamic system
D) A rigid vessel

Fig. 2. Sample question assessing understanding of thermodynamic systems.

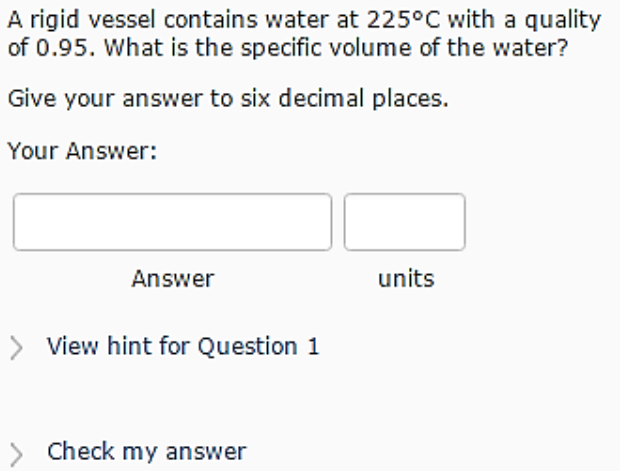

Fig. 3. Sample question assessing a fundamental understanding of the use of thermodynamic tables.

Finally, these series of questions are combined and applied to the thermodynamic systems as described above. These last problems involve multiple stages to arrive at a solution and are the stepping-stone to solving problems on the term tests and final exam. Additional guidance is provided in the problem solving process for these questions to ensure students are considering the necessary system and the processes. First, the system is described and a diagram is provided. Then, students are asked to check the system that they are analyzing, and the processes involved. Finally, they perform calculations to determine state properties so that they may apply work principles and the First Law of Thermodynamics. This process is illustrated using the example of a rigid vessel problem in Fig. 4, while Table 2 lists the questions and possible responses.

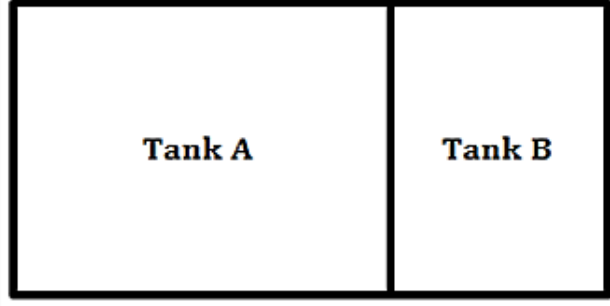

Two rigid tanks initially separated by a membrane are shown in the figure above. This will be referred to as State 1 . Both tanks contain carbon dioxide and the total mass of carbon dioxide in the two tanks is $100 \mathrm{~kg}$. At State 1, Tank A contains carbon dioxide at $P_{1 A}=6000 \mathrm{kPa}$. Tank $B$ has a volume of $V_{B 1}=0.08 \mathrm{~m}^{3}$ and contains saturated vapour carbon dioxide at $-10^{\circ} \mathrm{C}$. The membrane is punctured so that the contents of the two tanks mix and come to equilibrium. This shall be referred to as State 2 . At this point, the carbon dioxide is a saturated vapour at a

temperature of $0^{\circ} \mathrm{C}$.

Fig. 4. Information relating to a sample rigid vessel problem.

Table 2: Introduction to Thermal Sciences curriculum summary.

\begin{tabular}{|c|c|}
\hline Question & Possible Responses \\
\hline $\begin{array}{l}\text { Consider the substance } \\
\text { described in the question. } \\
\text { Will you be using the } \\
\text { thermodynamic tables or the } \\
\text { ideal gas assumption to solve } \\
\text { this question? }\end{array}$ & $\begin{array}{l}\text { - Thermodynamic tables } \\
\text { - Ideal gas law }\end{array}$ \\
\hline $\begin{array}{l}\text { Identify the system described } \\
\text { in the question. }\end{array}$ & $\begin{array}{l}\text { - Rigid vessel } \\
\text { - Piston-cylinder } \\
\text { - Open cycle } \\
\end{array}$ \\
\hline $\begin{array}{l}\text { Identify the process(es) from } \\
\text { State } 1 \text { to State } 2 .\end{array}$ & $\begin{array}{l}\text { - Isothermal } \\
\text { - Mixing } \\
\text { - Isobaric } \\
\text { - Constant volume } \\
\text { - Spring } \\
\text { - Polytropic } \\
\end{array}$ \\
\hline $\begin{array}{l}\text { Define the state of the } \\
\text { substance(s) }\end{array}$ & $\begin{array}{l}\text { - Saturated liquid } \\
\text { - Compressed liquid } \\
\text { - Saturated vapour } \\
\text { - Superheated vapour }\end{array}$ \\
\hline $\begin{array}{l}\text { Determine specific volume, } \\
\text { specific internal energy, or } \\
\text { specific enthalpy at each state. }\end{array}$ & Insert numerical value. \\
\hline $\begin{array}{l}\text { Determine the work and heat } \\
\text { transfer. }\end{array}$ & Insert numerical value. \\
\hline
\end{tabular}

Mastery of learning is achieved through solving multiple repetitive, but varied problems. While instantaneous feedback is provided in the Self Assessments modules, feedback can also be given at the end of a quiz to demonstrate to students where corrective action is required. 


\subsection{Implementation in an E-Learning Environment}

The PSI method discussed in Section 2 is easily implemented in the Brightspace Learning Environment with some modifications, to adapt the technique to the features within the learning management system, as well as within the context of an Engineering undergraduate course. Formative assessments are administered using the Self Assessments tool, providing students with instant feedback and directing them to correct their mistakes. These assessments are made continuously available to students so that students have the flexibility to master them on their own time. When they have sufficiently mastered the content in the Self Assessments, students are required to take a formative assessment on which they are evaluated. These evaluated assessments are accessed in the Quizzes tool and are not intended to be similar to term tests. These are simply checks to ensure students have understood the course material and are designed to be fairly short.

The tutorial will be implemented along with written assignments and tests throughout the term. In some ways, the tutorial may be perceived as adding to students' workloads. However, this is not the intention. The thermodynamics tutorial is designed to enhance the learning experience and ensure that all students have additional tools to support their mastery of the fundamental concepts.

\section{DATA COLLECTION AND DISCUSSION}

Although the design of this tutorial was still in progress, two quizzes were administered on a trial-basis to the students taking the 2016 Winter term course offering of Introduction to Thermal Sciences. At the end of the term, a survey was given to students to collect data with respect to students' perceptions on their motivations for participating in the online quizzes; their overall performance; and their ease of use of the online quizzes. The survey contained 19 statements in which students were asked to rate their agreement on a 5-point Likert scale, ranging from strongly agree to strongly disagree, with an option to choose neutral/undecided. Examples of the survey questions are listed in Table 3. Students' responses for these questions are illustrated in the bar graph in Fig. 5.

Although the data set is small, and students were only exposed to two online quizzes, it is helpful to consider the findings as we prepare to use the tutorial in the upcoming Summer term.
Table 3: Introduction to Thermal Sciences Curriculum summary.

\begin{tabular}{|l|l|}
\hline Label & \multicolumn{1}{|c|}{ Statement } \\
\hline A & The online quizzes helped prepare for tests. \\
\hline B & $\begin{array}{l}\text { I was happy with my performance on the } \\
\text { term tests. }\end{array}$ \\
\hline C & $\begin{array}{l}\text { I was happy with my performance on the } \\
\text { online quizzes. }\end{array}$ \\
\hline D & $\begin{array}{l}\text { The design of the online quizzes supports } \\
\text { my learning. }\end{array}$ \\
\hline E & $\begin{array}{l}\text { I found the content of the online quizzes } \\
\text { helpful for my learning. }\end{array}$ \\
\hline F & $\begin{array}{l}\text { I expect to do better in this course because } \\
\text { of the online quizzes. }\end{array}$ \\
\hline G & $\begin{array}{l}\text { It was difficult for me to navigate the online } \\
\text { quizzes. }\end{array}$ \\
\hline H & $\begin{array}{l}\text { It was difficult for me to access the online } \\
\text { quizzes. }\end{array}$ \\
\hline I & I prefer doing quizzes on paper than online. \\
\hline J & I enjoyed doing the online quizzes. \\
\hline
\end{tabular}

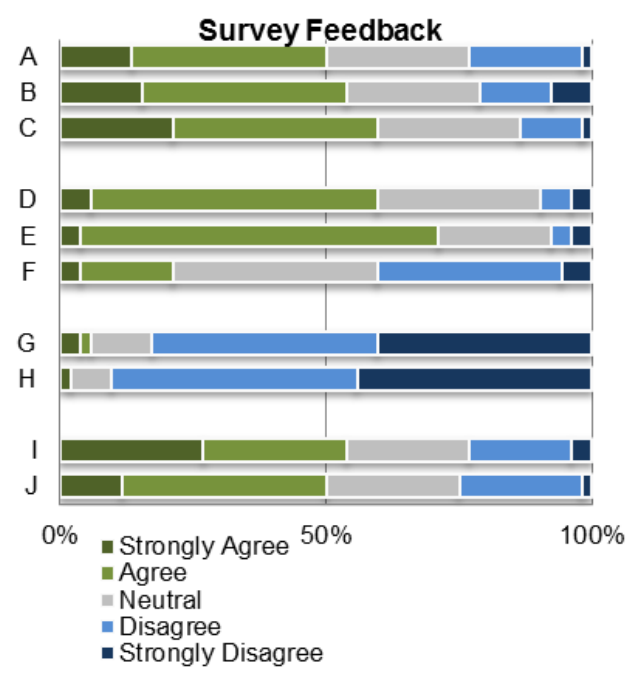

Fig. 5. Chart describing feedback corresponding to statements in Table 2

Overall, students expressed mixed feedback with regards to the effect of the online quizzes in studying for term tests. Almost $40 \%$ of students agreed that the online quizzes were useful in preparation for summative assessments at the end of each chapter. However, 27\% of the students were neutral, while the remainder did not believe that the quizzes were useful in preparing for the term tests. The same trend is observed when students were asked if they were happy with their performance on quizzes and on the term tests. Similarly, students were asked to express their thoughts on their overall performance in the course. Although the majority of the students disagreed that they expected to do better in the course because of the online quizzes, the majority also 
agreed that the content on the quizzes was helpful in learning course content and that, overall, the quizzes supported their learning.

Finally, the survey gauged whether the online quizzes were easy to use. For the most part, students expressed that the quizzes were easy to access, as well as easy to navigate. Data also shows that students were willing to participate in online quizzes because they wanted to do well in the course, although they preferred to be assessed on paper rather than online.

In addition to the quantitative data, students were given the option to respond to two qualitative questions in regards to suggestions for improvements for the online quizzes, and any additional comments. Written responses suggested that improvements could be made to the feedback provided on the quiz to facilitate the diagnosis of which corrective actions students should take.

Overall, although students' responses to the online quizzes were mixed, the general consensus indicates that the online quizzes were helpful, and supported students' learning.

\section{CONCLUSIONS AND RECOMMENDATIONS}

Using a mastery-based approach in an Engineering undergraduate course is feasible with the use of learning management systems to facilitate interactions between instructors and students. The tutorial design described in this paper assesses the mastery of fundamental concepts and skills required in the first year thermodynamics course in the Faculty of Engineering at the University of Manitoba. The tutorial is implemented using the Self Assessment and the Quizzes tools in D2L's Brightspace Learning Environment, and is intended to support student learning and prepare students for summative assessments. Instant feedback on formative assessments shows students where corrective action is required and ensures that all students have the opportunity to acquire a firm understanding of preliminary fundamental thermodynamic concepts.

Although students' responses to the piloted online quizzes were mixed, the majority of students found that the assessment tools were relatively simple to access and navigate, and that the online quizzes were helpful, and supported their learning. Further research will be conducted on providing constructive feedback on the online quizzes that enables students to better diagnose which corrective actions should be taken when they make an error. As well, we will investigate whether masterybased assessments should be used in higher-level undergraduate courses.

This work is being conducted to provide additional tools to Engineering students to ensure that they have every opportunity to master the fundamental knowledge and skills that they require to be successful Engineering students, and to become efficacious Engineers. It is part of the continuum of educational initiates that are ongoing in the Faculty of Engineering at the University of Manitoba, and shows our commitment to the pursuit of excellence in Engineering Education.

\section{Acknowledgements}

This research is being funded by the NSERC Chair in the Centre for Engineering Professional Practice and Engineering Education in the Faculty of Engineering at the University of Manitoba. We are grateful for his support.

\section{References}

[1] S. Anselmo and Bloom, "Bloom's "Human Characteristics and School Learning" in Perspective", Educational Researcher, vol. 10, no. 10, p. 29, 1981.

[2] J.M. Bekki, O. Dalrymple, C. S. Butler, "A mastery-based learning approach for undergraduate engineering programs", IEEE Frontiers in Education Conference (FIE), 2012, pp. 1-6.

[3] M. Cochran and P. Heron, "Development and assessment of research-based tutorials on heat engines and the second law of thermodynamics", Am. J. Phys., vol. 74, no. 8, p. 734, 2006.

[4] M. Ee, W. Yeoh, Y. Boo and T. Boulter, "Examining the effect of time constraint on the online mastery learning approach towards improving postgraduate students' achievement", Studies in Higher Education, pp. 1-17, 2016.

[5] T. R. Guskey, "Benjamin S. Bloom's contributions to curriculum, instruction and school learning," in Proceedings of the American Educational Research Association, Seattle, WA, 2001

[6] T. R. Guskey, "Lessons of Mastery Learning", Educational Leadership, vol. 68, no. 2, pp. 52-57, 2016.

[7] M. Ironsmith and M. Eppler, "FACULTY FORUM: Mastery Learning Benefits Low-Aptitude Students", Teaching of Psychology, vol. 34, no. 1, pp. 28-31, 2007.

[8] J. van Merriënboer, "Perspectives on problem solving and instruction", Computers \& Education, vol. 64, pp. 153-160, 2013.

[9] M. Shaw, Engineering problem solving. Norwich, N.Y.: Noyes Pub./William Andrew Pub., 2001.

[10] B. Wong and L. KANG, "Mastery learning in the context of university education", Journal of the NUS Teaching Academy, vol. 2, no. 4, pp. 206-222, 2016.

[11] R. Yudkowsky, Y. Park, M. Lineberry, A. Knox and E. Ritter, "Setting Mastery Learning Standards", Academic Medicine, vol. 90, no. 11, pp. 1495-1500, 2015. 